\title{
Estudante universitário: características e experiências de formação
}

\author{
Adriana Cristina Boulhoça Suebiro 1
}

\begin{abstract}
Mercuri, E. \& Polydoro, S. A. J. (Org.). (2004). Estudante universitário: características e experiências de formação. Taubaté: Cabral Editora e Livraria Universitária.
\end{abstract}

Diante da constatação de que o estudante universitário tem sido pouco focalizado nos estudos referentes ao sistema de ensino superior, visto que, na maioria das vezes, são apenas participantes das pesquisas, as organizadoras desse livro objetivam promover uma aproximação de produções científicas, nas quais o objeto central de estudo é o universitário. Ao lado disso, pretendem favorecer a discussão sobre os conhecimentos necessários para a compreensão de suas necessidades. Convictas de que o conhecimento sobre esses estudantes envolve a identificação de suas características ao chegar à universidade, o conhecimento sobre a forma como se dá a sua interação com a nova realidade educacional e suas conseqüências em relação à formação, Mercuri e Polydoro organizam os textos de modo a oferecer um panorama sobre as diferentes questões focalizadas nesta área de estudo. Os nove capítulos, escritos por profissionais de Psicologia e áreas afins, referem-se a estudos desenvolvidos por meio de diversas abordagens teóricas e metodológicas, caracterizando-se como estudos independentes, porém relevantes para uma compreensão mais aprofundada das mudanças ocorridas no nível superior de ensino.

No capítulo inicial, Leandro de Almeida e Ana Paula Soares apresentam uma análise da literatura sobre como se processa a transição dos estudantes do Ensino Secundário para o Ensino Superior, destacando que ela não se circunscreve apenas a aspectos acadêmicos, mas integra questões pessoais e sociais. Assim, descrevem os principais desafios e dificuldades do processo de transição e adaptação do estudante ao ensino superior, especialmente, no que se refere ao rendimento escolar e desenvolvimento psicossocial. Em suas conclusões, fazem referência às práticas e serviços institucionais dirigidos, por algumas instituições, aos estudantes mais fragilizados neste processo, destacando que os resultados da investigação realizada permitem concluir que nem todos os universitários precisam do mesmo tipo de apoio nessa nova fase de suas vidas, já que suas motivações, habilidades cognitivas, background acadêmico, expectativas e níveis de autonomia acabam diferenciando-os. A investigação de Almeida e Soares sugere, ainda, que uma das formas de favorecer a integração e a adaptação desses estudantes está em propiciar oportunidades para sua participação social e desenvolvimento acadêmico.
Cônscios da necessidade de estudos que apresentem o universitário como foco de análise e, especificamente, dos aspectos psicológicos envolvidos na trajetória de formação desses estudantes e da necessidade de que as instituições planejem e implantem estratégias mais adequadas ao desenvolvimento integral dos mesmos, Soely A. J. Polydoro e Ricardo Primi trazem, no segundo capítulo, os resultados obtidos em uma pesquisa que buscou verificar a contribuição das características de personalidade para a adaptação ao Ensino Superior. Os resultados obtidos indicam, por um lado, que a crença dos estudantes em suas capacidades, o desejo de mudanças e a competência em organizar estratégias de ação associam-se a uma tendência maior de adaptação. Por outro lado, características como a organização, persistência e independência relacionam-se à maior dedicação de tempo aos estudos. Polydoro e Primi encerram sua contribuição, salientando a necessidade de outros estudos que abordem esse tema, tendo em vista que a integração do estudante é um processo multifacetado que exige uma abordagem mais ampla do que a relatada, em sua avaliação e intervenção.

Considerando a importância da motivação dos estudantes para que a aprendizagem se concretize e os resultados de pesquisas recentes sobre o tema, Rita da Penha Campos Zenorini e Acácia Aparecida Angeli dos Santos analisam, no capítulo três, as relações entre os diferentes tipos de metas de realização (aprender e performance) e o uso de estratégias de aprendizagem no desempenho acadêmico de alunos universitários. Os resultados evidenciam uma correlação significativa entre a utilização de estratégias de aprendizagem (cognitivas complexas e metacognitivas) com o desempenho acadêmico. O estudo revela ainda que os alunos orientados à meta performance apresentam correlação negativa com a maioria dos fatores da escala de estratégias e com o desempenho acadêmico e que as mulheres mostram-se mais orientadas para a meta aprender, utilizam mais freqüentemente estratégias de aprendizagem e apresentam um desempenho acadêmico mais elevado.

Isabel Cristina Dib Bariani traz sua contribuição para a compreensão do estudante universitário, no capítulo quatro, apresentando estudos oriundos da literatura sobre os estilos cognitivos. A autora considera que os estilos cognitivos são uma dentre as muitas variáveis

${ }^{1}$ Endereço para correspondência:

E-mail: dricbs@yahoo.com.br 
que interferem no processo ensino-aprendizagem e que os conhecimentos existentes sobre os mesmos podem viabilizar práticas educativas mais eficazes e contribuir para a formação dos universitários. Um exemplo do quanto os conhecimentos disponíveis podem ter um grande valor é, segundo Bariani, a possibilidade de elaborar cuidadosamente as estruturas curriculares, tanto em seus fundamentos filosóficos e psicopedagógicos, quanto no que se refere ao planejamento das grades curriculares e das atividades programadas no cotidiano das universidades.

Defendendo que a formação profissional no ensino superior deveria articular a competência técnica à social, Zilda A. P. Del Prette e Almir Del Prette relatam, no capítulo cinco, alguns de seus esforços na análise e promoção do desenvolvimento interpessoal do estudante universitário e propõem a experiência do Programa de Desenvolvimento Interpessoal Profissional. Trata-se de um programa de intervenção desenvolvido para suprir déficits interpessoais e maximizar o desempenho social em diferentes contextos. Segundo os autores, a inserção de programas desse tipo no currículo de ensino superior parece uma alternativa promissora para garantir um repertório de habilidades e competência interpessoal necessário para que se integre ao processo educativo, uma formação mais ampla do estudante, maximizando a qualidade de sua atuação profissional em termos técnicos e éticos.

Tratando do impacto da formação universitária sobre o estudante, Graziela Giusti Pachane traz, no capítulo seis, uma análise das contribuições da formação universitária nas mudanças pessoais do estudante, apontando as contínuas rupturas às quais estão expostos e suas conseqüências. A pesquisa realizada pela autora revela que a diversidade de relacionamentos pessoais e a aquisição de novos conhecimentos foram importantes para o desenvolvimento dos alunos pesquisados, enquanto profissionais e indivíduos, sendo ainda percebidas outras alterações em relação a características pessoais, tais como personalidade e atitudes.

No capítulo seguinte Camila Alves Fior e Elizabeth Mercuri apresentam uma série de estudos desenvolvidos a fim de se compreenderem as alterações nos estudantes universitários, considerando o contexto no qual encontram-se inseridos como uma fonte potencial de influência sobre suas transformações cognitivas e afetivas durante os anos de graduação, a exemplo do capítulo anterior. Além disso, as autoras relatam os resultados de um estudo qualitativo que buscou investigar as relações entre o envolvimento dos estudantes em atividades não obrigatórias e suas mudanças pessoais. Os resultados indicam que a participação e o envolvimento em atividades não obrigatórias parecem desencadear mudanças pessoais que favorecem a adaptação e integração ao contexto universitário.

O capítulo oito é resultado de um levantamento que visou conhecer os problemas enfrentados pelos universitários brasileiros na fase que estavam vivenciando e as estratégias que auxiliavam na solução dos mesmos. O estudo realizado por Elisabete Monteiro de Aguiar Pereira evidencia que os problemas mais freqüentes dos universitários são os relacionados aos estudos e às relações interpessoais e de socialização, seguidos pelos materiais e os de identidade e que a maioria deles procura resolvê-los pessoalmente ou com a ajuda de pessoas próximas.

No capítulo final do livro suas organizadoras recorrem aos resultados de uma série de estudos cujo foco é a evasão para compreenderem como ocorre o processo de decisão de permanência/evasão ao longo da trajetória de graduação do estudante. As autoras concluem a análise desses estudos, destacando o papel das variáveis associadas à definição do curso nesse processo decisório.

Estudante universitário: características e experiências de formação é um livro que revela uma preocupação em se compreender como o estudante universitário percebe e vivencia essa nova fase de sua vida, repleta de novos e complexos desafios acadêmicos, sociais, pessoais e vocacionais. Nesse sentido, trata-se de uma obra bastante interessante para profissionais e estudantes que, de alguma maneira, estejam envolvidos com o ensino superior e que compartilhem a necessidade de lançar um olhar mais aprofundado sobre como as mudanças intra e interpessoais se processam nessa fase. Sua organização permite que, ao final da obra, o leitor disponha de uma série de informações importantes sobre como o estudante universitário tem sido compreendido, o que faz com que o livro seja uma excelente fonte de referência.

Recebido em maio de 2004 Aprovado em junho de 2004

Sobre a autora:

Adriana Cristina Boulhoça Suehiro é psicóloga e mestranda pelo Programa de Estudos Pós-Graduados em Psicologia da Universidade São Francisco. 